Clough: We could detect such bottom crevasses by radio-echo sounding but could not accurately determine their width. We have detected bottom crevasses at the hinge line of the ice shelf and believe they are formed by this mechanism although our survey did not extend up-stream far enough to determine positively that the hinge-line is the point of origin. It is unlikely that we can discriminate between these crevasses and those that may form by other mechanisms unless their physical characteristics are quite different (e.g. height of formation, width, etc.).

\title{
RADIO DEPTH SOUNDING ON BARNES IGE CAP
}

\author{
By R. A. O'Neil and S. J. Jones \\ (Glaciology Division, Inland Water Directorate, Department of the Environment, \\ Ottawa $\mathrm{K}_{\mathrm{IA}}$ oE 7 , Canada)
}

Abstract. In May 1974 two radio depth sounders were used on the Barnes Ice Cap, Baffin Island. One was a S.P.R.I. $35 \mathrm{MHz}$ sounder and the other was a unit operating at $620 \mathrm{MHz}$. Bottom reflections were observed with both systems at similar depths, indicating no significant velocity change between the two frequencies. Used with a Motorola range positioning system, the $620 \mathrm{MHz}$ unit proved an excellent depth-survey vehicle. Results along the so-called surge profile (Holdsworth, 1973) are presented. Depth and attenuation values are compared with previous data.

\section{REFERENCE}

Holdsworth, G. 1973. Evidence of a surge on Barnes Ice Cap, Baffin Island. Canadian Zournal of Earth Sciences, Vol. 10, No. 10, p. $1565-74$.

\section{DISCUSSION}

J. W. Clough: Was the wide-angle velocity measurement you report a fixed-end profile or a common-reflection-point profile? Do you have any plans to measure the anisotropy in relative permitivity $\epsilon$ for single ice crystals or ice with strong fabric?

S. J. Jones: The velocity measurements were made with a fixed-end profile. We have made preliminary tests on two single ice crystals and found an anisotropy of $<2 \%$ in the lowfrequency value of $\epsilon$.

J. G. PAREN: Your measurement of the attenuation at $35 \mathrm{MHz}$ on polycrystalline ice grown in the laboratory is indeed in accord with the measurements of Westphal (unpublished, reported by Evans ( 1965$)$ ) on polar ice at $15^{\circ} \mathrm{MHz}$ and the measurements on ice from polar regions obtained by Paren (1973) and Fitzgerald and Paren (1975) at lower frequencies. The measurements do not correspond, however, to those expected from pure, slowly grown laboratory single crystals if there are no further dispersions above the Debye dispersion. They would more likely correspond to polycrystalline ices grown by Boned and Barbier (1973). Were your ices formed from supercooled water?

Jones: The ice was not deliberately formed from supercooled water.

P. Gloersen: You mentioned "inverse-cube scattering"; for what variable? 
JoNes: For the scattered power received back at the receiver.

T. Hughes reported work by a graduate student at the Institute for Arctic and Alpine Research on numerical modelling of the Barnes Ice Cap which indicated different dynamic states in two portions of the ice cap over the last century as also suggested by the work of Holdsworth.

\title{
REFERENCES
}

Boned, C., and Barbier, A. 1973. A study of the change with time of the dielectric properties of polycrystalline ice. (In Whalley, E., and others, ed. Physics and chemistry of ice: papers presented at the Symposium on the Physics and Chemistry of Ice, held in Ottawa, Canada, I4-18 August 1972. Edited by E. Whalley, S. F. Fones, L. W. Gold. Ottawa, Royal Society of Canada, p. 208-I I.)

Evans, S. 1965. Dielectric properties of ice and snow-a review. Journal of Glaciology, Vol. 5, No. 42, p. 773-92.

Fitzgerald, W. J., and Paren, J. G. 1975. The dielectric properties of Antarctic ice. Fournal of Glaciology, Vol. i 5 , No. 73 , p. $39-48$.

Paren, J. G. 1973. The electrical behavior of polar glaciers. (In Whalley, E., and others, ed. Physics and chemistry of ice: papers presented at the Symposium on the Physics and Chemistry of Ice, held in Ottawa, Canada, $14^{-18}$ August 1972. Edited by E. Whalley, S. J. Jones, L. W. Gold. Ottawa, Royal Society of Canada, p. 262-67.)

\section{RADIO-ECHO SOUNDING ON SOUTH CASCADE GLACIER, WASHINGTON, USING A LONG-WAVELENGTH, MONO-PULSE SOURCE}

\author{
By Raymond D. Watts, Anthony W. England, \\ (U.S. Geological Survey, Denver, Colorado 80225, U.S.A.) \\ Roger S. Vickers \\ (Stanford Research Institute, Menlo Park, California 94025, U.S.A.) \\ and Mark F. Meier \\ (U.S. Geological Survey, Tacoma, Washington 98402, U.S.A.)
}

Abstract. A short-pulse, long-wavelength radio-echo sounder has successfully measured the ice depth on the South Cascade Glacier. Depths up to $250 \mathrm{~m}$ were determined with resolution of about $5 \%$. Bottom returns were clear and almost never ambiguous. Their accuracy was confirmed by comparison with hot-point drilling results. The secret for successful sounding in temperate glaciers is the use of a sufficiently low center frequency. Five megahertz was most successful. Tests at $15 \mathrm{MHz}$ indicated an increase in coherent clutter which rendered the bottom return observable only with prior knowledge of its location. The cause of the clutter is probably water-filled voids in the ice which behave as Rayleigh scatterers.

The sounding system consists of an avalanche-transistor transmitter, which delivers a pulse to an acute-angle crossed-wire antenna. The pulse is shaped and given its centerfrequency characteristics by the resonant properties of the antenna. The transmitting and receiving antennas are identical, consisting of wires and lumped resistors. The resistors reduce antenna ringing, thereby maintaining as short a pulse as possible. The receiver consists of an oscilloscope and a Polaroid camera. No preamplification is required for depths up to $250 \mathrm{~m}$, but may be necessary for deeper glaciers. 